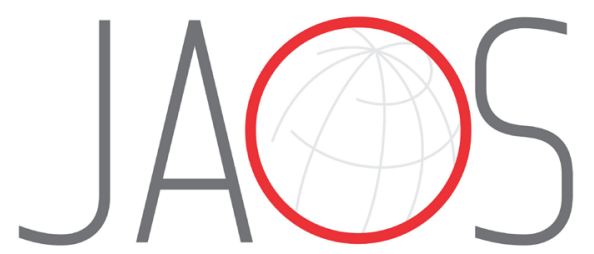
JOURNAL OF APPLIED ORAL SCIENCE

\title{
Microbial profile of symptomatic pericoronitis lesions: a cross-sectional study
}

\section{Abstract}

Marcus Heleno Borges RIBEIRO' 1

Paulo Cesar RIBEIRO' ${ }^{1}$

Belén RETAMAL-VALDES ${ }^{2}$

Magda FERES ${ }^{2}$

Antonio CANABARRO1,3,4 iD
Objective: The microbial composition of pericoronitis (Pc) is still controversial; it is not yet clear if the microbial profile of these lesions is similar to the profile observed in periodontitis ( $P d)$. Therefore, the aim of the present study was to describe the microbial profile of Pc lesions and compare it directly with that of subjects with Pd. Methodology: Subjects with Pc and Pd were selected, and subgingival biofilm samples were collected from (i) third molars with symptomatic Pc (PC-T), (ii) contralateral third molars without Pc (Pc-C) and (iii) teeth with a probing depth $>3 \mathrm{~mm}$ from subjects with $\mathrm{Pd}$. Counts and proportions of 40 bacterial species were evaluated using a checkerboard DNA-DNA hybridization technique. Results: Twenty-six patients with Pc and 18 with Pd were included in the study. In general, higher levels of microorganisms were observed in Pd. Only Actinomyces oris and Eubacterium nodatum were present in higher mean counts in the Pc-T group in comparison with the Pc-C and Pd-C groups $(\mathrm{p}<0.05)$. The microbiota associated with Pc-T was similar to that found in Pc-C. Sites with Pc lesions had lower proportions of red complex in comparison with the Pd sites. Conclusion: The microbiota of Pc is very diverse, but these lesions harbour lower levels of periodontal pathogens than Pd.

Keywords: Pericoronitis. Periodontitis. Microbiota.
Submitted: April 26, 2019 Modification: July 11, 2019

Accepted: July 22, 2019

Corresponding address: Antonio Canabarro.

Universidade Veiga de Almeida - Rua Ibituruna 108 20271-901 - Maracanã - Rio de Janeiro - RJ - Brasil. Phone: +552125748871 e-mail: canabarro@uva.br.
'Universidade Iguaçu, Curso de Odontologia, Departamento de Cirurgia Oral, Nova Iguaçu, Rio de Janeiro, Brasil.

2Universidade Guarulhos, Divisão de Pesquisa Odontológica, Departamento de Periodontia,

Guarulhos, São Paulo, Brasil.

3Universidade Veiga de Almeida, Programa de Pós-Graduação em Odontologia, Rio de Janeiro, Rio de Janeiro, Brasil.

${ }^{4}$ Universidade Estado do Rio de Janeiro, Departamento de Procedimentos Clínicos Integrados, Rio de Janeiro, Rio de Janeiro, Brasil. 


\section{Introduction}

Pericoronitis $(\mathrm{Pc})$ is an infectious condition involving the soft tissue around the crown of a partially erupted tooth. ${ }^{1}$ Thus, a high prevalence of Pc during the eruption of primary and permanent dentition could be expected. However, this condition rarely occurs in primary dentition; it is mainly associated with the eruption of the mandibular third molars ${ }^{2}$ and is more commonly reported in females. ${ }^{3}$ Although Pc may affect the patient's quality of life because it is often followed by discomfort, pain, bleeding, halitosis or even trismus, this condition is often neglected in daily clinical practice. ${ }^{1}$

Third-molar eruption normally occurs in people between 18 and 25 years old, but problems with the eruption process are frequently observed. ${ }^{2} \mathrm{~A}$ study that evaluated 245 cases of Pc found 35\% of these cases occurred in patients between 20 and 29 years old. The occlusal surface of the affected tooth is often covered by gingival tissue, which favors the accumulation of food and biofilm, promoting the development of an infectious process. ${ }^{2}$ Vertically impacted molars are more likely to present Pc. ${ }^{4}$ Severe cases have an associated risk of systemic dissemination of the infection. ${ }^{5}$

Very few studies to date have analyzed the microbial composition associated with Pc. ${ }^{2,6-11}$ Overall, studies have shown that periodontal pathogens are common in third-molar periodontal sites in subjects without periodontal diseases. ${ }^{9-11}$ Previous studies have demonstrated the presence of gramnegative anaerobes and mobile forms of spirochetes in periodontal sites with $\mathrm{PC}^{6,7}$ and concluded that the composition of the biofilm associated with Pc seems to be similar to that found in periodontitis (Pd). ${ }^{8-10}$ However, these studies evaluated only a few biofilm samples and microbial species ${ }^{6,7}$ or were not Pc patients and Pd patients comparative studies, ${ }^{8-11}$ which could preclude a complete understanding on the microbial profile of Pc. Therefore, this study aims to describe the microbial profile of Pc lesions and compare it directly with the microbial profile of subjects with Pd.

\section{Methodology}

\section{Study design and settings}

This is a bicentric cross-sectional study with a control-to-case ratio of 0.7 . This study was conducted at Veiga de Almeida University (Universidade Veiga de Almeida - UVA, Rio de Janeiro, RJ, Brazil) and Iguaçu University (Universidade Iguaçu - UNIG, Nova Iguaçu, RJ, Brazil) from January to March 2015. The study protocol was previously approved by the Human Research Ethics Committee of Veiga de Almeida University, Rio de Janeiro, RJ, Brazil (protocol number 962399).

\section{Participants}

Systemically healthy volunteers diagnosed with untreated Pc or Pd were selected from the population that searched for dental treatment. Subjects who fulfilled the inclusion criteria were invited to participate in the study. All eligible subjects were thoroughly informed of the nature, potential risks, and benefits of their participation in the study and then signed an Informed Consent Form. Detailed medical and dental histories were obtained, and a full-mouth periodontal examination was performed.

The inclusion criteria for the study groups were: (I) Pericoronitis test (Pc-T): at least one mandibular third molar with partial eruption and gingival tissue covering the crown of the tooth with one or more of the following symptoms: pain, edema and spontaneous bleeding; (II) Pericoronitis control (PC-C): at least one contralateral third molar of the same Pc patient with no periodontal pocket depth (PPD $<3 \mathrm{~mm}$ ) and no bleeding on probing. If this tooth was absent, data of contralateral first or second molar were used; and (III) Periodontitis control (Pd-C): adults ( $>35$ years old) with $\geq 2$ teeth with $\geq 1$ detectable buccal or interproximal site with a clinical attachment level $(\mathrm{CAL}) \geq 3 \mathrm{~mm}$ and a PPD $>3 \mathrm{~mm} \cdot{ }^{12}$

The exclusion criteria were: presence of Pd (for Pc groups), traumatic injury of the soft tissues, periodontal treatment in the previous six months, smoking, pregnancy, lactation, use of prostheses, all systemic conditions that could affect the periodontal microbial composition (for example HIV, diabetics, etc.), treatment with nonsteroidal anti-inflammatory drug and antibiotic medications or mouthwashes in the previous six months.

A total of 44 volunteers participated in the study, 26 with Pc (16 females and 10 males, aged between 19 and 29 years old) and 18 with Pd ( 12 females and 6 males, aged between 35 and 67 years old). The mean ages ( \pm standard deviation) of the Pc and Pd groups 
were $25.46 \pm 2.87$ and $48.89 \pm 13.02$, respectively $(p>0.05)$. Pd also showed a mean PPD of $4.72 \pm 1.40$ $\mathrm{mm}$.

\section{Microbiological monitoring - sample collection}

Subgingival biofilm samples were collected from two periodontal sites per volunteer, including:

\section{Pc groups:}

(I) PC-T - the deepest periodontal site of the mandibular third molar with Pc and (II) Pc-C - one site with a PPD $<3 \mathrm{~mm}$ and no bleeding on probing of the mandibular third molar in the contralateral quadrant.

\section{Pd group:}

(III) the site with the deepest periodontal pocket in the mouth (PPD $\geq 4 \mathrm{~mm}$ ).

After the clinical examination, all the teeth were dried and isolated using cotton rolls. After supragingival plaque removal, subgingival biofilm samples were collected using sterile paper points (size 45) (Dentsply Sirona, Pirassununga, SP, Brazil) inserted into each site for 30 seconds, as previously described. ${ }^{13,14}$ The samples were immediately placed into individual tubes containing $150 \mu$ of TE buffer solution (10 mM Tris-HCL; Life Technologies, Carlsbad, CA, USA) and $1 \mathrm{mM}$ of EDTA (Labsynth, Diadema, SP, Brazil; pH 7.6). $100 \mu$ of $0.5 \mathrm{M} \mathrm{NaOH}$ (Labsynth) was added to each tube to preserve the bacterial DNA. All the tubes were stored under refrigeration at $-20^{\circ} \mathrm{C}$ until the samples were analyzed using checkerboard DNADNA hybridization at the Laboratory of Microbiology, Immunology and Molecular Biology of Universidade de Guarulhos (Guarulhos, SP, Brazil).

\section{Checkerboard DNA-DNA hybridization}

Counts and proportions of 40 bacterial species were determined in each sample, using the checkerboard DNA-DNA hybridization technique. ${ }^{15,16}$ The samples were boiled for $10 \mathrm{~min}$ and neutralized using $0.8 \mathrm{~mL}$ of $5 \mathrm{M}$ ammonium acetate. The released DNA was then placed into the extended slots of a Minislot 30 apparatus (Immunetics, Marlborough, MA, USA), concentrated on a $15 \times 15 \mathrm{~cm}$ positively charged nylon membrane (Boehringer Mannheim, Indianapolis, IN, USA), and were fixed to the membrane by baking it at $120^{\circ} \mathrm{C}$ for $20 \mathrm{~min}$. The membrane was then placed

\begin{tabular}{|c|c|c|c|}
\hline Species & Strains & Species & Strains \\
\hline Actinomyces group & & Orange complex (cont.) & \\
\hline Actinomyces gerencseriae & $23860^{\mathrm{a}}$ & Fusobacterium nucleatum ssp nucleatum & $25586^{a}$ \\
\hline Actinomyces israelii & $12102^{\mathrm{a}}$ & Fusobacterium nucleatum ssp polymorphum & $10953^{\mathrm{a}}$ \\
\hline Actinomyces naeslundii & $12104^{a}$ & Fusobacterium nucleatum ssp vincentii & $49256^{a}$ \\
\hline Actinomyces oris & $43146^{\mathrm{a}}$ & Fusobacterium periodonticum & $33693^{\mathrm{a}}$ \\
\hline Purple complex & & Parvimonas micra & $33270^{\mathrm{a}}$ \\
\hline Actinomyces odontolyticus & $17929^{a}$ & Prevotella intermedia & $25611^{a}$ \\
\hline Veillonella parvula & $10790^{\mathrm{a}}$ & Prevotella nigrescens & $33563^{a}$ \\
\hline Yellow complex & & Streptococcus constellatus & $27823^{\mathrm{a}}$ \\
\hline Streptococcus gordonii & $10558^{a}$ & Red complex & \\
\hline Streptococcus intermedius & $27335^{a}$ & Tannerella forsythia & $43037^{a}$ \\
\hline Streptococcus mitis & $49456^{\mathrm{a}}$ & Porphyromonas gingivalis & $33277^{\mathrm{a}}$ \\
\hline Streptococcus oralis & $35037^{a}$ & Treponema denticola & $\mathrm{B} 1^{\mathrm{b}}$ \\
\hline Streptococcus sanguinis & $10556^{\mathrm{a}}$ & Other species & \\
\hline Green complex & & Eubacterium saburreum & $33271^{\mathrm{a}}$ \\
\hline \multirow{2}{*}{ Aggregatibacter actinomycetemcomitans $a+b$} & $43718^{a}$ & Gemella morbillorum & $27824^{\mathrm{a}}$ \\
\hline & $29523^{a}$ & Leptotrichia buccalis & $14201^{\mathrm{a}}$ \\
\hline Capnocytophaga gingivalis & $33624^{a}$ & Neisseria mucosa & $19696^{a}$ \\
\hline Capnocytophaga ochracea & $33596^{a}$ & Prevotella melaninogenica & $25845^{\mathrm{a}}$ \\
\hline Capnocytophaga sputigena & $33612^{a}$ & Propionibacterium acnes $1+\|$ & $11827^{\mathrm{a}}$ \\
\hline Eikenella corrodens & $23834^{a}$ & & $11828^{a}$ \\
\hline Orange complex & & Selenomonas noxia & $43541^{a}$ \\
\hline Campylobactergracilis & $33236^{a}$ & Streptococcus anginosus & $33397^{a}$ \\
\hline Campylobacter rectus & $33238^{a}$ & Treponema socranskii & $\mathrm{S} 1^{\mathrm{b}}$ \\
\hline Campylobacter showae & $51146^{\mathrm{a}}$ & & \\
\hline Eubacterium nodatum & $33099^{a}$ & & \\
\hline
\end{tabular}

Figure 1- Bacterial strains used for the preparation of DNA probes. Species are grouped according to the microbial complexes ${ }^{18}$ 
in a Miniblotter 45 (Immunetics) with the lanes of DNA at $90^{\circ}$ to the lanes of the device. Digoxigeninlabelled whole genomic DNA probes for 40 bacterial species (Figure 1) were hybridized in individual lanes of the Miniblotter. After the hybridization, the membranes were washed at high stringency, and the DNA probes were detected using the antibody to digoxigenin conjugated with alkaline phosphatase. Chemiluminescence detection was then performed. The last two lanes in each run contained standards at concentrations of $10^{5}$ and $10^{6}$ cells of each species. Signals were evaluated visually by comparison with the standards at the $10^{5}$ and $10^{6}$ bacterial cells for the test species on the same membrane by a calibrated examiner. The sensitivity of this assay was adjusted to allow detection of $10^{4}$ cells of a given species by adjusting the concentration of each DNA probe. This procedure was carried out to provide the same sensitivity of detection for each species.

\section{Statistical methods}

The mean counts ( $\times 10^{5}$ cells) of the individual bacterial species were averaged within each subject and then across the subjects in the different clinical groups. Similarly, the percentage of the total DNA probe counts was determined initially in each site, then per subject and averaged across the subjects in the three groups. The individual proportions of each species were added to determine the proportions of each microbial complex. ${ }^{17}$ The significance of the differences between the groups was assessed using one-way ANOVA test. In addition, a t-test was used to determine significant differences between the pairs of groups. Adjustments for multiple comparisons were performed when the 40 bacterial species were evaluated simultaneously. ${ }^{17}$ All the analyses of this study were conducted using a statistical program developed by Sigmund Socransky (The Forsyth Institute, Cambridge, MA, USA). The significance level was set at $5 \%$.

\section{Results}

Figure 2 shows the mean counts ( $\times 10^{5}$ cells) of the sites colonized by the 40 species evaluated in the subgingival plaque samples from the Pc-C, Pc-T and $\mathrm{Pd}-\mathrm{C}$ groups. The species present in the highest levels in Pc-T were Actinomyces oris, Eikenella corrodens, Eubacterium nodatum, Fusobacterium nucleatum spp. nucleatum, Treponema denticola and Eubacterium saburreum. $A$. oris and $E$. nodatum were present in higher mean counts in the Pc-T group in comparison with the Pc-C and Pd-C groups $(p<0.05)$. The microbiota associated with the $\mathrm{PC}-\mathrm{T}$ group was very similar to that found in Pc-C. Most of the bacterial species evaluated in the study were found in higher counts in the $\mathrm{Pd}-\mathrm{C}$ group, and 20 of them were significantly higher in this group compared with the Pc-T group, including Actinomyces gerencseriae, A. oris, Veillonella parvula, Streptococcus sanguinis, Capnocytophaga gingivalis, Capnocytophaga ochracea, Capnocytophaga sputigena, Campylobacter rectus, Campylobacter showae, E. nodatum, Fusobacterium nucleatum. spp. polymorphum, Fusobacterium nucleatum. spp. vicentii, Parvimonas micra, Prevotella intermedia, Porphyromonas gingivalis, Treponema denticola, Leptotrichia buccalis, Propionibacterium acnes, Streptococcus anginosus and Treponema socranskii $(p<0.05)$.

The mean proportions of the microbial complexes in the different groups are described in Figure 3. The red complex pathogens were higher in $\mathrm{Pd}-\mathrm{C}$ than $\mathrm{Pc}-\mathrm{T}$ and $\mathrm{Pc}-\mathrm{C}$ groups $(\mathrm{p}<0.05)$. A similar trend was also observed for the green complex $(p<0.05)$. However, a tendency towards a higher proportion of yellow complex species in the PC groups was noticed $(p=0.09)$.

\section{Discussion}

The results of this study showed Pc sites harbored a quite diverse microbiota; nonetheless, with a lower degree of dysbiosis than that observed in Pd lesions. Pc biofilm samples had lower levels and proportions of putative and traditional periodontal pathogens and a tendency towards higher levels of the healthassociated yellow complex species than Pd lesions.

The red complex, which harbors the three most traditional periodontal pathogens ( $P$. gingivalis, $T$. denticola and Tannerella forsythia), ${ }^{18}$ was present in higher counts in Pd patients, compared with both the Pc groups. Although previous studies have shown a high number of $T$. forsythia in Pc patients, ${ }^{11,19}$ this study could not confirm these findings. It is important to highlight that $P$. gingivalis, an anaerobic gramnegative bacteria, and $T$. denticola, an anaerobic 
Figure 2- Mean counts $\left(10^{5}\right)$ of 40 subgingival species in each study group. The species were ordered according to the microbial complexes described by Socransky, et al. ${ }^{18}$ (1988). The significance of differences between groups was assessed using one-way ANOVA test. Different letters indicate significant differences between pairs of groups (t-test, $p<0.05$ ). Letters were color coded to indicate the different groups: green for $\mathrm{Pc}-\mathrm{C}$, red for $\mathrm{Pc}-\mathrm{T}$, and blue for $\mathrm{Pd}-\mathrm{C}$. Pc-C: Pericoronitis control group; Pc-T: Pericoronitis test group; Pd-C: Periodontitis control group

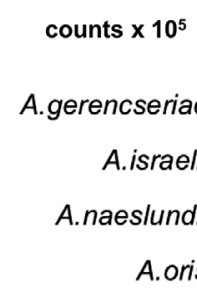

A.odontolyticus

V.parvulla

S. gordonii

S.intermedius

S.mitis

S.oralis

S. sanguinis

A. actinomycetencomytans

C.gingivalis

C.ochracea

C.sputigena

E.corrodens

C.gracilis

C.rectus

C.showae

E.nodatum

F.nucleatum.ssp.nucleatum

F.nucleatum.ssp.polymorphum

F.nucleatum.ssp.vincentii

F.periodonticum

P.micra

P.intermedia

P.nigrescens

S. constellatus

T.forsythia

P.gingivalis

T.denticola

E.saburreum

G.morbillorum

L.buccalis

P.acnes

P.melaninogenica

N.mucosa

S. anginosus

S.noxia

T.socranskii
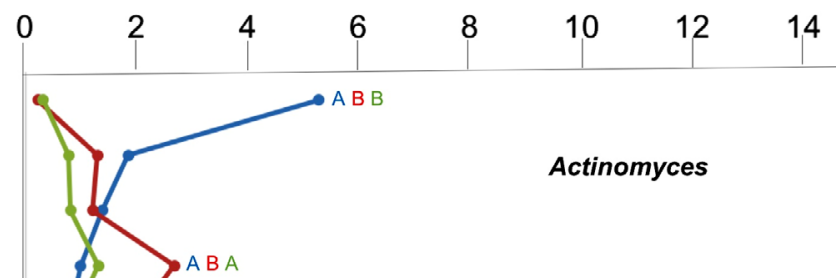

Actinomyces

Purple

$A B B$

Yellow

Green

Orange
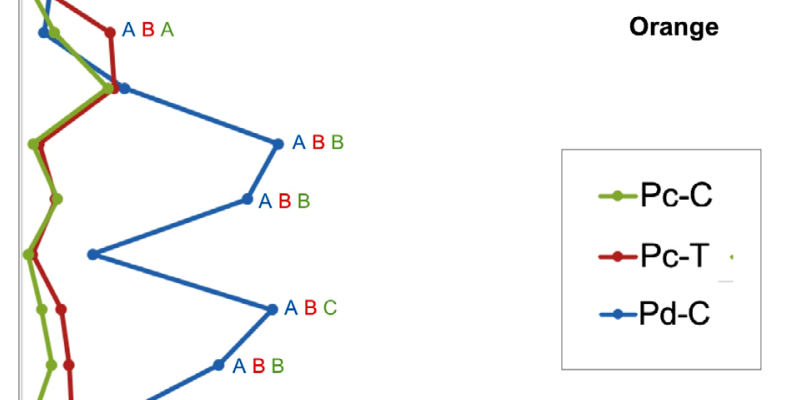

Red
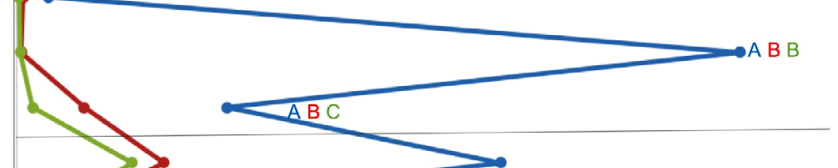

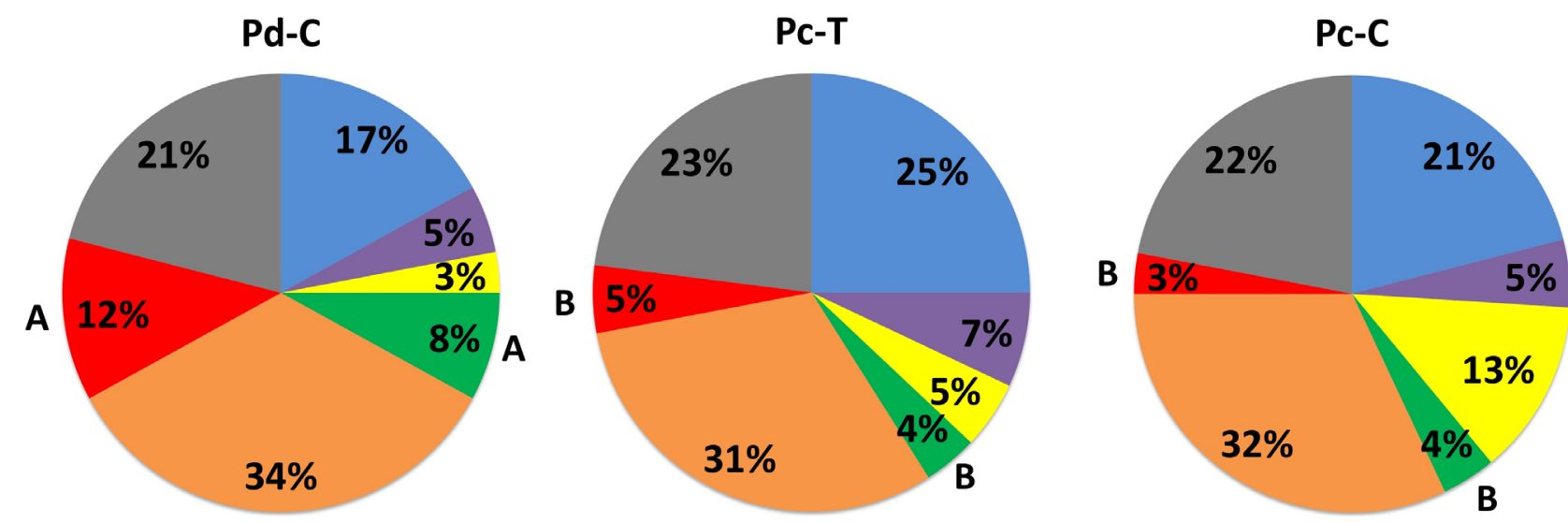

Figure 3- Mean proportions of the microbial complexes in each study group. The colors represent different microbial complexes ${ }^{18}$ and Actinomyces species (blue). The significance of differences between groups was sought using the one-way ANOVA. The differences were only found for red and green complexes. Different letters indicate significant differences between pairs of groups ( $t$-test, $p<0.05)$. Pc-C: Pericoronitis control group; Pc-T: Pericoronitis test group; Pd-C: Periodontitis control group

gram-negative spirochete, have been considered key periodontal pathogens. ${ }^{20}$ Those are frequently found to co-exist in deep periodontal pockets. ${ }^{21}$ Such interaction between them can contribute to Pd progression. ${ }^{22} T$. socranskii, another anaerobic gram-negative spirochete, is also considered a periodontal pathogen ${ }^{23,24}$ associated with $\mathrm{Pc}^{25}$ and was also found in higher proportions and levels in the Pd group. Interestingly, these 3 microorganisms together ( $P$. gingivalis, $T$. denticola, and $T$. socranskii) were correlated with abnormal periodontal clinical parameters and have been associated with periodontal tissue loss. ${ }^{23}$

In fact, few published studies compared putative pathogens in healthy and Pc sites. Some of these studies have used conventional culture-dependent methods that many times fail to detect strict anaerobe pathogens, ${ }^{6,7}$ at least one study neglected to include a control group without $\mathrm{Pc}$, hampering the interpretation of the results. ${ }^{8}$ Another study compared healthy and symptomatic Pc sites, and the results supported the hypothesis that the pericoronal region harbors putative periodontal pathogens, ${ }^{10}$ and may provide a favored niche for periodontal pathogens in a healthy oral environment. ${ }^{9}$

Discussing the clinical findings of this study in relation to the microbial profiles observed in the various lesions is important. First, these findings suggest the biofilm associated with Pc apparently does not have a strong potential to trigger irreversible periodontal destruction since it does not harbor high levels of major periodontal pathogens and maintains good levels of host-compatible microorganisms. As $\mathrm{Pc}$ is an acute disease, one could hypothesize that time between the development of the lesion and its treatment for the massive growth of key periodontal pathogens was insufficient. Besides that, the prophylactic surgical removal of teeth with Pc is frequently performed in dental practice. ${ }^{26}$ In addition, antibiotic treatment must be considered in patients whose Pc infections were disseminated and have invaded deeper oral spaces. ${ }^{26}$ Most Pc lesions are associated with a subgingival anaerobic niche created by the overgrowth of gingival tissues. Nonetheless, the differences between the microbial load of Pd and Pc shown in this study suggest the antibiotic protocols required to treat these conditions may not be the same. Future studies addressing this topic would help to guide clinical practice.

The main strength of this study is that, to the best of our knowledge, this is the first study to comprehensively assess the microbial composition of Pc lesions and to compare this profile to that found in Pd. One limitation of the study design is the relatively small sample size, due to the difficulty in selecting Pc cases in daily clinical practice. Furthermore, this study shows results for the 40 bacterial species proposed by Socransky, et al. ${ }^{18}$ (1988) as it is well established that the periodontal microbiome comprises more taxa than those included in this group of bacterial species. ${ }^{27}$ Nevertheless, this panel of species has been successfully used as a biological marker for many studies of periodontal disease risk and treatment. ${ }^{28,29} \mathrm{~A}$ comprehensive study showed it covers approximately $60 \%$ of the bacterial genera present in the oral cavity. ${ }^{30}$

Few studies have identified periodontal bacteria in pericoronitis samples, but it seems that pericoronal sites can harbor several pathogens. A recent study showed some periodontopathic bacteria and herpesviruses occurred concomitantly in pericoronitis 
samples. ${ }^{11}$ Such herpesviral-bacterial interaction could be an important feature of pericoronitis and should be further studied.

In conclusion, Pc microbiota is diverse, but these lesions harbor lower levels of periodontal pathogens than those of Pd.

\section{Acknowledgement}

The authors thank FAPERJ (grant number E-26/101.454/2010), CAPES, CNPq and LAOHA for financial support.

\section{References}

1- Magraw CB, Golden B, Phillips C, Tang DT, Munson J, Nelson BP, et al. Pain with pericoronitis affects quality of life. J Oral Maxillofac Surg. 2015;73(1):7-12.

2- Nitzan DW, Tal O, Sela MN, Shteyer A. Pericoronitis: a reappraisal of its clinical and microbiologic aspects. J Oral Maxillofac Surg. 1985;43(7):510-6.

3- Singh $P$, Nath $P$, Bindra S, Rao SS, Reddy KV. The predictivity of mandibular third molar position as a risk indicator for pericoronitis: a prospective study. Natl J Maxillofac Surg. 2018;9(2):215-21.

4- Katsarou T, Kapsalas A, Souliou C, Stefaniotis T, Kalyvas D. Pericoronitis: a clinical and epidemiological study in greek military recruits. J Clin Exp Dent. 2019;11(2):e133-7.

5- Douglass AB, Douglass JM. Common dental emergencies. Am Fam Physician. 2003;67(3):511-6.

6- Labriola D, Mascaro J, Alpert B. The microbiologic flora of orofacial abscess. J Oral Maxillofac Surg. 1983;41(11):711-4.

7- Leung WK, Theilade E, Comfort MB, Lim PL. Microbiology of the pericoronal pouch in mandibular third molar pericoronitis. Oral Microbiol Immunol. 1993;8(5):306-12.

8- White RP Jr, Madianos PN, Offenbacher S, Phillips C, Blakey GH, Haug $\mathrm{RH}$, et al. Microbial complexes detected in the second/third molar region in patients with asymptomatic third molars. J Oral Maxillofac Surg. 2002;60(11):1234-40

9- Mansfield JM, Campbell JH, Bhandari AR, Jesionowski AM, Vickerman MM. Molecular analysis of $16 \mathrm{~S}$ rRNA genes identifies potentially periodontal pathogenic bacteria and archaea in the plaque of partially erupted third molars. J Oral Maxillofac Surg. 2012;70(7):1507-14.

10- Rajasuo A, Sihvonen OJ, Peltola M, Meurman JH. Periodontal pathogens in erupting third molars of periodontally healthy subjects. Int J Oral Maxillofac Surg. 2007;36(9):818-21.

11- Jakovljevic A, Andric M, Knezevic A, Milicic B, Beljic-Ivanovic K, Perunovic $\mathrm{N}$, et al. Herpesviral-bacterial co-infection in mandibular third molar pericoronitis. Clin Oral Investig. 2017;21(5):1639-46.

12- Papapanou PN, Sanz M, Buduneli N, Dietrich T, Feres M, Fine DH, et al. Periodontitis: Consensus report of workgroup 2 of the 2017 World Workshop on the Classification of Periodontal and Peri-Implant Diseases and Conditions. J Periodontol. 2018;89(Suppl 1):S173-82.
13- Hallström H, Persson GR, Strömberg U, Twetman S, Renvert S. Reproducibility of subgingival bacterial samples from patients with peri-implant mucositis. Clin Oral Investig. 2015;19(5):1063-8.

14- Socransky SS, Haffajee AD, Smith C, Martin L, Haffajee JA, Uzel NG, et al. Use of checkerboard DNA-DNA hybridization to study complex microbial ecosystems. Oral Microbiol Immunol. 2004;19(6):352-62. 15- Mestnik MJ, Feres M, Figueiredo LC, Duarte PM, Lira EA, Faveri $M$. Short-term benefits of the adjunctive use of metronidazole plus amoxicillin in the microbial profile and in the clinical parameters of subjects with generalized aggressive periodontitis. J Clin Periodontol. 2010;37(4):353-65

16- Socransky SS, Smith C, Martin L, Paster BJ, Dewhirst FE, Levin AE. "Checkerboard" DNA-DNA hybridization. Biotechniques. 1994;17(4):788-92.

17- Socransky SS, Haffajee AD, Smith C, Dibart S. Relation of counts of microbial species to clinical status at the sample sites. J Clin Periodontol. 1991;18(10):766-75.

18- Socransky SS, Haffajee AD, Cugini MA, Smith C, Kent RL Jr. Microbial complexes in subgingival plaque. J Clin Periodontol. 1988;25(2):134-44.

19- Sencimen M, Saygun I, Gulses A, Bal V, Acikel CH, Kubar A. Evaluation of periodontal pathogens of the mandibular third molar pericoronitis by using real time PCR. Int Dent J. 2014;64(4):200-5. 20- Dashper SG, Seers CA, Tan KH, Reynolds EC. Virulence factors of the oral spirochete Treponema denticola. J Dent Res. 2011;90(6):691-703. 21- Ng HM, Kin LX, Dashper SG, Slakeski N, Butler CA, Reynolds EC. Bacterial interactions in pathogenic subgingival plaque. Microb Pathog. 2016;94:60-9.

22- Zhu Y, Dashper SG, Chen YY, Crawford S, Slakeski N, Reynolds EC. Porphyromonas gingivalis and Treponema denticola synergistic polymicrobial biofilm development. PLoS One. 2013;8(8):e71727. 23- Takeuchi $Y$, Umeda M, Sakamoto $M$, Benno $Y$, Huang $Y$, Ishikawa I. Treponema socranskii, Treponema denticola, and Porphyromonas gingivalis are associated with severity of periodontal tissue destruction. J Periodontol. 2001;72(10):1354-63.

24- Mineoka T, Awano S, Rikimaru T, Kurata H, Yoshida A, Ansai T, et al. Site-specific development of periodontal disease is associated with increased levels of Porphyromonas gingivalis, Treponema denticola, and Tannerella forsythia in subgingival plaque. J Periodontol. $2008 ; 79(4): 670-6$.

25- Dabu B, Mironiuc-Cureu M, Jardan D, Szmal C, Dumitriu S. Identification of four Treponema species in subgingival samples by nested-PCR and their correlation with clinical diagnosis. Roum Arch Microbiol Immunol. 2012;71(1):43-7.

26- Adeyemo WL. Do pathologies associated with impacted lower third molars justify prophylactic removal? A critical review of the literature. Oral Surg Oral Med Oral Pathol Oral Radiol Endod. 2006;102(4):448-52. 27- Pérez-Chaparro PJ, Gonçalves C, Figueiredo LC, Faveri M, Lobão E, Tamashiro $N$, et al. Newly identified pathogens associated with periodontitis: a systematic review. J Dent Res. 2014;93(9):846-58. 28- Teles R, Teles F, Frias-Lopez J, Paster B, Haffajee A. Lessons learned and unlearned in periodontal microbiology. Periodontol 2000. 2013;62(1):95-162.

29- Feres M, Figueiredo LC, Soares GM, Faveri M. Systemic antibiotics in the treatment of periodontitis. Periodontol 2000. 2015;67(1):131-86 30- Socransky SS, Haffajee AD, Smith C, Martin L, Haffajee JA, Uzel NG, et al. Use of checkerboard DNA-DNA hybridization to study complex microbial ecosystems. Oral Microbiol Immunol. 2004;19(6):352-62. 